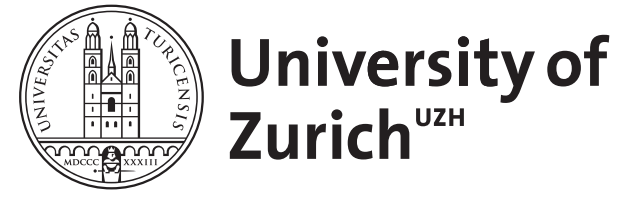

Zurich Open Repository and Archive

University of Zurich

University Library

Strickhofstrasse 39

CH-8057 Zurich

www.zora.uzh.ch

Year: 2008

\title{
The role of the plural system in Romance
}

Stark, Elisabeth

Posted at the Zurich Open Repository and Archive, University of Zurich

ZORA URL: https://doi.org/10.5167/uzh-10740

Book Section

Published Version

Originally published at:

Stark, Elisabeth (2008). The role of the plural system in Romance. In: Detges, Ulrich; Waltereit, Richard. The paradox of grammatical change : perspectives from Romance. Amsterdam/Philadelphia: John Benjamins Publishing, 57-84. 


\title{
THE PARADOX OF GRAMMATICAL CHANGE
}

PERSPECTIVES FROM ROMANCE

\author{
Edited by \\ ULRICH DETGES \\ Ludwig-Maximilians-Universität München \\ RICHARD WALTEREIT \\ Newcastle University
}




\section{CONTENTS}

THE ROLE OF THE PLURAL SYSTEM IN ROMANCE ${ }^{1}$

Introduction

Ulrich Detges and Richard Waltereit

Syntactic change from within and from without syntax:

A usage-based analysis

Richard Waltereit and Ulrich Detges

On explaining the rise of $c^{\prime}$ est-clefts in French Andreas Dufter

The role of the plural system in Romance Elisabeth Stark

Morphological developments affecting syntactic change Maria Goldbach

Grammaticalisation within the IP-domain Susann Fischer

Imperfect systems and diachronic change Giampaolo Salvi

From temporal to modal: Divergent fates of the Latin synthetic pluperfect in Spanish and Portuguese Martin Becker

Non-lexical core-arguments in Basque, Romance and German Hans-Ingo Radatz

Towards a comprehensive view of language change:

Three recent evolutionary approaches

Esme Winter-Froemel

Subject Index

\author{
ELISABETH STARK \\ Freie Universität Berlin
}

This paper presents a diachronic formal morphosyntactic analysis of the role of the functional projection $P l / P l^{*}$ in Romance indefinite nominals, responsible for number and the countability distinction. Reinterpreting the complex system of indefinite nominal determination in two central Romance languages, viz. French and Italian, which both feature an indefiniie article and a 'partitive article' as a device of 'nominal classification' in a broad sense in contrast to Romance languages without such an element, viz. Spanish, it argues that this 'classification system' arose when nominal declension in Latin was partially or completely lost. The application of the latest minimalist assumptions on agreement processes in the syntax both to modern Romance languages and to (Late) Latin allows us to describe and explain the obvious differences between French, Italian and Spanish and to relate them to the interaction of gender and number marking in Romance indefinite nominals.

\section{Introduction: Different systems of indefinite nominal determiners in}

Romance nominals as results of language change

As I have repeatedly shown, ${ }^{2}$ there is considerable cross-linguistic variation in indefinite nominal determination in Romance, despite some well-known generalizations assuming homogeneous semantic and syntactic systems of nominal determination for all Romance languages (e.g. Chierchia 1998, Longobardi 2001a). See the data in (1a-f):

1 This article was presented in two versions, the first at the Workshop on Grammatical Language Change and its Explanations in Saarbrücken in September 2005 and the second at the Intemational Workshop on the Typological Comparison of Italian and German at the Johann-Wolfgang-Goethe Universität, Frankfurt am Main, in February 2006. Special thanks for very helpful comments go to Guido Mensching and Natascha Pomino from Freie Universität Berlin as well as to Ulrich Detges, Richard Waltereit, Michele Loporcaro, Ulrich Wandruszka, Günter Grewendorf, Alessandra Tomaselli, Cecilia Poletto, Carme Picallo and one anonymous reviewer. All errors and shortcomings are, of course, mine.

${ }^{2}$ Cf. some earlier work on the cross-linguistic divergence in Romance indefinite nominals and its syntactic implications, cf. Stark (2006 and forthcoming). 
(1) a. Has visto *(un) águila? As-tu vu*(un) aigle? Hai visto * (un) aquila?

"Did you see an eagle?"

b. Compro pan

J'achète *(du) pain.

Compro (del) pane.

"I buy (some) bread"

c. Me falta agua.

Il me faut *(de l')eau.

Mi occorre (dell')acqua.

"I need (some) water"

d. Veo (a unos) estudiantes en el edificio.

Je vois "(des) étudiants dans le bâtiment. Vedo (degli) studenti nell'edificio.

"I see (some) students in the building".

(Spanish)

(French)

(Italian)

(Spanish)

(French)

(Italian)

(Spanish)

(French)

(Italian)

(Spanish)

(French)

(Italian)

In fact, there are two main differences to be observed:

Firstly, bare noun phrases in argument position occur in Spanish and Italian (and other Romance languages) under very restricted grammatical conditions: bare plurals surface mostly postverbally with subject and object function regardless of the lexical entry of the noun (normally with non-specific interpretation of the nominal, cf. 1d). Bare singulars are also possible with 'mass-denoting nouns' (not with 'entity-denoting nouns' in so-called singular countable NPs, see 1a) postverbally with subject and object function (see $1 \mathrm{~b}$ and 1c), again with non-specific interpretation of the nominal. Conversely, the only Romance language which almost never permits bare noun phrases in argument position is French.

Secondly, every Romance language possesses a so-called indefinite article derived from the Latin numeral unus, "one", which accompanies singular count noun phrases. However, only two of the three Romance languages discussed here, i.e. French and Italian, have a further indefinite determiner, the.so-called 'partitive article' derived from the composition of Latin $d e$ and the definite article. It marks indefinite non-countable singular noun phrases, usually with 'mass-denoting nouns', in pre- and postverbal subjects and objects. It is obligatory in French and (still) optional in Italian, where its use is increasing constantly, however (cf. Korzen 1996). Functionally, its morphological plural (Fr. des, It. dei, degli) is to be considered as the plural of the indefinite article (see examples lb-d).

If we compare this picture to Latin, the main differences or changes within nominals become immediately obvious: for indefinite nominals as well as definite ones, obligatory determination has become a property of Romance languages in contrast to Latin. See example (2):
(2) ...ubi se tamen montes illi, inter quos ibamus, aperiebant et faciebant vallem infinitam ingens, planissima et valde pulchram, et trans vallem apparebat mons sanctus Dei Syna.

"...where in the meantime the mountains, between which we were going, opened out and formed an endless valley - huge, very flat and very beautiful - and across the valley there appeared Sinai, the holy mountain of God."

(Vincent 1997:156, from the Peregrinatio Aegeriae, late $4^{\text {th }}$ century AD)

The first mention of the valley (et faciebant vallem... 'and they formed a valley') in a postverbal object does not show any indefinite marking (via aliquis, quidam 'anyone', 'someone' or else), and even when this discourse referent is referred to anaphorically (et trans vallem apparebat... 'and across the valley there appeared...') in a prepositional adverbial, it is left without a definite determiner and not referred to via (clitic) pronouns. ${ }^{3}$ In short: Latin did not need (obligatory) overt marking of nominal determination in argumental noun phrases and did not have third person pronouns (cf. Vincent 1997 and others). The Romance languages now do have overt nominal determination, which is obligatorily overt in certain syntactic contexts, and they also have (clitic) third person pronouns. This change is of considerable typological impact and can be summed up under diverse headings such as 'from synthetic to analytical coding', from 'dependent-marking' to 'head-marking' or, in a minimalist framework, as changes in the lexical feature structure (see below) of universal functional heads such as $\mathrm{C}, \mathrm{T}, v$ and D. Alternatively, one could think, as Vincent 1997 did for definite nominals, of the rise of new functional categories in Romance via reanalysis of ambiguous syntactic input or, less radically, of a different parameterized projection of functional categories in different languages. Whatever name we give to the change, it has to be described and explained in a way that satisfies both the aspect of the initial innovation, which is most probably linked to universal cognitive principles, and the later individual mutations of the different Romance linguistic systems. These differ to a considerable extent, both in their history and in their present morphosyntactic make-up, and their linguistic evolution can therefore not be subsumed under some vague general functional coding or decoding strategies, as will be shown below. In the following I shall in particular argue in favour of a formal account of the morphosyntactic changes leading to the new feature structure of a functional head ' $\mathrm{Pl}$ ' in addition to the already (now widely accepted) projection NumP inside nominals ${ }^{4}$, and their language-specific features triggering different overt realizations of nominal determination in different Romance languages.

${ }^{3}$ Prepositional phrases are typical syntactic contexts in which nominal determination does not need to be marked overtly, even in languages with nominal determination, cf. modern Romanian. However, modem French, Italian or Spanish would require a definite determiner in the case in question.

${ }^{4}$ Cf. especially Ritter (1993, 1995), Picallo (1991, 2005), Munn \& Schmitt (2005) and Zamparelli $(2004,2005)$ for the discussion of NumP. 
The remainder of this article is structured as follows: section 2 gives an overview of the nominal morphology and indefinite determiners in French, Italian and Spanish compared with the Latin declensional system in order to reveal two fundamental correlations. Section 3 introduces the formal model following Chomsky's most recent proposals for modelling agreement processes and for deriving the correct morphological and semantic quantification of nominals (section 3.1), before applying it to indefinite nominals in modern French, Italian and Spanish. Section 4 tries to retrace the morphosyntactic evolution from Latin to modern Romance languages by applying the 'probe model' to questions of diachronic syntax, especially to the functional projection $\mathrm{Pl}\left({ }^{*}\right)$, after which the conclusions given in section 5 will summarize the findings and relate them to some parallel approaches in the recent generative literature.

\section{A functional 'explanation': Romance indefinite determiners as \\ 'classification devices'}

I have repeatedly pointed to the fact that Romance indefinite determiners can be understood as 'classification devices' in a broad sense, coding what Seiler in his functional universal dimensions calls "apprehension": 5

APPREHENSION is the universal operational dimension with corresponding subdimensions which explicate the grasping and representation of concepts corresponding to objects or things by means of language. (Seiler 1986:145)

In Latin, the basic notional distinction between an individualized object and some uncontoured substance could be coded by using gender and number, especially by using the semantic and morphological residue of the IndoEuropean opposition between neuter and masculine/feminine. See examples $(3 a-c)$

(3) a. caseus "one single (piece of) cheese", olea "olive" / "olive tree"

b. caseum "cheese as a substance", oleum "oil"

c. acinus/acinum "berтy",

acina "grape",

frumentum "wheat",

frumenta "com"

(3a) shows lexical roots with masculine and feminine gender, resulting in 'entity-denoting nouns', whereas the nouns from the same root in (3b) with

${ }^{5}$ Cf. Seiler (1986) and Stark (2005, 2006, and forthcoming).

${ }^{6}$ Cf. in detail Hofmann \& Szantyr ((1997) [1965]:7-10), Meisterfeld (1998:56ff.) and for Late Latin analogical neuter plurals following the same pattern cf. Morani (2000:228). neuter gender are 'mass-denoting nouns'. ${ }^{7}$ In addition, (3c) shows the wellknown 'collective' semantics of the Latin neuter plural ending in - $a$ (cf. Schön 1971, Windisch 1973). Although theses oppositions are not systematic, the Latin neuter and especially the Latin neuter plural in - $a$ - both unambiguously marked in spoken and written varieties - can be re-interpreted as a partly generalised 'classification system' mainly denoting the opposition between 'single, contoured object' (e.g. one piece of cheese, one olive, one berry) and 'noncontoured substance' (e.g. cheese, oil) or 'collective' (grapes).

Furthermore, this important semantic opposition is as much related to gender as to number: the Latin plural is neither automatically interpreted as additive (cf. Link 1991) nor restricted to 'entity-denoting nouns'. See examples (4a-b):

(4) a. frigora caloresque "an intense heat and cold": plural indicating intensification

b. acquae "waters", cerae "wax tablets": different appearances of a substance

Although the Latin plural can have a sortal reading, bare plurals of abstract or 'mass denoting-nouns' are not automatically re-categorized as they for instance are in modern Romance languages (compare Fr. huile "oil", des huiles "different sorts of oil"). Virtually any Latin noun can be pluralized, and frequent occurrences of plurals of 'mass-denoting nouns' or abstract nouns, as in (4) above, are in fact attested. ${ }^{9}$ This indicates that Latin had no grammaticalized 'countability distinction' at the level of noun phrases.

In contrast to Latin, modern Standard French, Italian and Spanish have almost completely lost the possibility of 'classification' via gender/number alternations (and declension class). The main morphological changes in the nominal system from Latin to Romance are well-known and comprise the

${ }^{7}$ In describing the facts in these terms, following Löbel (1993:192/f.) and with reference to Gil's (1987) typology I assume a fundamental difference between the lexical categories 'massdenoting', 'entity-denoting' and 'abstract noun' $(\mathrm{N})$, which derive from characteristics of the denoting', 'entity-denoting' and 'abstract noun' $(\mathrm{N})$, which derive from characteristics of the
potential (extra-linguistic) referents and are based on denotational properties of the head noun, and the countability or non-countability of entire noun phrases. This last opposition is a grammatical category or a feature which depends on the internal syntactic structure of the noun phrase and is mainly characterized by compatibility with certain indefinite determiners (French/Italian: un/uno 'one', 'a', INDEF.ART vs. du/del 'of.the', PART = partitive article). This assumption is justified by the fact that virtually any noun in Romance languages (like in any language with a grammaticalized countability distinction in this sense) can in principle appear in any kind of noun phrase, cf. German Nach dem Unfall lag jede Menge Auto herum, "After the accident, there was much car lying around".

${ }^{8}$ Cf. Kühner \& Stegmann ( $\left.{ }^{3} 1955: 69,73\right)$, Hofmann \& Szantyr ((1997) [1965]:18, 21).

${ }^{9}$ Cf. Iturnioz Leza (1986:295f.): "This individualization strategy [ = pluralization of abstract nouns, E.S.] is more widespread in the classical languages (Greek. Latin) than in modern German or any other European language; it is thus often difficult to translate an abstract [plural, E.S.] NP without changing its number: [...] Asperitates viarum et angustiae [...] 'The roughness(es) and narrowness(es) of the ways"'. 
complete loss of morphological case, a reduction of gender (especially loss of the neuter), contrasted with a solid formal preservation of number, but now with only the 'additive plural meaning' left. In addition, modern Standard French shows the complete loss of the declension classes (already lost in Old French, cf. Delfitto \& Schroten 1991:180f.). Gender and number are usually marked (in the phonetic code) by prenominal determiners only. Modern Standard Italian is different from French in that it has preserved 3 main declension classes, 2 overtly marked genders and overt number marking. However, the declensional endings $-a$ and $-e$ are far from being unambiguous markers of singular or plural, as they can either indicate feminine singular, (rarely) masculine singular or feminine plural $(-a)$ or masculine singular or feminine plural $(-e)$. The morpheme - $o$ unambiguously indicates singular, but both masculine and (rarely) feminine gender. Just like Italian, modern (European) Standard Spanish has 3 main declension classes, 2 overtly marked genders and overt number marking. It is unambiguous with respect to number marking ("plurality is manifested consistently with the suffix /-s/", Harris 1992:67). See (5a-c):

(5) a. un ami $(\mathrm{m}) /$ une amie (f.) - des ami(e) [ãnami / ynami -dezami]

"a male friend"/"a female friend", "male/female friends"

b. Sg.: $-o /-a /-e$ Pl.: $-i /-a /-e$

$$
\begin{aligned}
& \text { libr-o-libr-i(m) } \\
& \text { "book" - "books" } \\
& \text { cas-a-cas-e (f.) } \\
& \text { "house" - "houses" } \\
& \text { can-e - can-i }(\mathrm{m} \text {.) } \\
& \text { "dog" - "dogs" }
\end{aligned}
$$

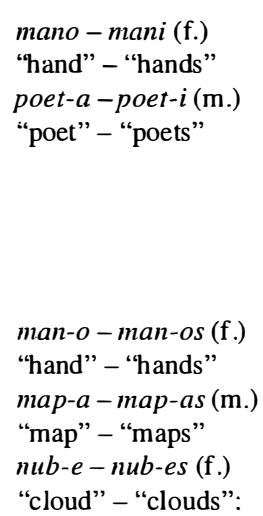

man-o-man-os (f.)

"hand" - "hands"

map-a-map-as $(\mathrm{m}$.)

"map" - "maps"

nub-e-nub-es (f.)

"cloud" - "clouds":

(Spanish)

Please note in $(5 b)$ the residue of the original Latin classification potential of the neuter plural in $-a$ as opposed to a regular plural form in $-i$ (originating in Late Latin, cf. Hofmann \& Szantyr (1997 [1965]:21) and reanalysed as feminine (plural), always indicating a collective or at least 'pair' reading). Some nouns ending in - $o$ (masculine singular), usually denoting concrete objects like body parts (It.: ginocchio "knee", orecchio "ear" and so on, also muro "wall" etc.), have a plural form in $-a$ when denoting a plurality, body parts or a 'collective reading'. However, they form a plural in $-i$ when used metaphorically to denote something similar in form but without a collective denotation (e.g. It.: le braccia denotes both arms of an animate being, whereas $i$ bracci denotes the arms of a river, It. le mura denotes the city wall, whereas $i$ muri denotes the single walls of a building). Unlike Italian, Spanish does not seem to preserve a certain 'classification potential' in nominal (declensional) endings; the only slight 'classification potential' left in Spanish is the erroneously named 'neuter' (deriving from the Latin neuter singular) in the pronominal system which refers to CPs, i.e. quotations, statements of fact etc. (cf. Picallo 2002). ${ }^{10}$

If we try to relate the findings concerning the paradigm of indefinite determiners with the nominal morphology shown by French, Italian and Spanish up to now, we can observe two important correlations:

Firstly, the possibility of having bare arguments, especially bare plurals in argument position (Italian, Spanish vs. French), correlates with the formal preservation of the Latin 'neuter' in nouns or pronouns, not only with the possibility of overt plural marking. " Secondly, the presence of a 'partitive article' explicitly coding non-countability (Italian, French vs. Spanish) correlates with ambiguous plural marking. ${ }^{12}$

If we try to explain the general language change from Latin towards Romance in relation to the re-structuring of nominal morphology and the grammaticalization of nominal determination for indefinite argument nominals too, we could now easily take up Givon's observations about the widespread grammaticalization of the numeral "one" into an indefinite article (cf. Givón 1981 ) and thus an indicator of countability via implicature ('if something can be quantified as being one element out of a set in contrast to two, three and so on, it is a member of a set of countable discrete entities'). This element could thus have compensated for the loss of the complex Latin declension and assumed the function of 'classification' in a broad sense. Even if this 'explanation' seems convincing at first sight, it leaves us with a lot of open questions and does not provide a satisfying structural descriptive analysis of the individual phenomena occurring in the morphosyntactic structure of the different Romance languages. In particular, the new syntactic property of obligatory coding of countability in Romance indefinite nominals in contrast to

\footnotetext{
${ }^{10}$ Spanish personal pronouns and demonstratives show a threefold morphological opposition, with forms ending in $-e$ for masculine singular, $-a$ for feminine singular, and $-o$ for the socalled 'neuter' (e.g. span. no quiero pensar más en él/ella/ello "I do not want to think about him/her/it any longer").
hilled 'neuter' (e.g. span.

11 Contrary to what is postulated in Schroten (2001).

${ }^{12} \mathrm{Cf}$. Stark (in prep.), with reference also to older stages of the Romance languages and the simultaneous development of the 'partitive article' and the loss of overt or unambiguous plural
} marking in French and Italian. 
Latin remains unexplained, and the considerable differences between the single Romance languages which we showed above in section 1 are completely neglected - as are the specific properties of many other languages which have grammaticalized "one" into an indefinite article and are nevertheless very different from Romance in many respects (English, German, Hebrew and so on). In addition, we have to bear in mind that "[u]seful or needed things are not sufficiently explained by their usefulness or the need for them" (Haspelmath 1999:188).

\section{A formal account of Romance indefinite nominals \\ 3.1 'Manufacturing plurality'}

Following the formal modelling of agreement in the latest versions of the minimalist program, ${ }^{13}$ lexical items and more generally heads "interact through agreement to influence the shape of syntactic structure and the process of semantic interpretation" (Pesetsky \& Torrego 2004:1). Lexical items can be described as having certain bundles of grammatical features, so-called $\varphi$ features, some valued, others unvalued (e.g. the number feature $N b$ on nouns is normally valued and can have the value singular, SING, or plural, PLUR, whereas it does not come already valued from the lexicon for determiners or adjectives, which accordingly have to agree with the noun in nominals, cf. Pesetsky \& Torrego 2004:1f.). Features can thus be described as attribute-value pairs. Moreover, features are considered to be either interpretable or uninterpretable: "This distinction is concerned with a different question: whether or not a feature of a particular lexical item makes a semantic contribution to the interpretation of that item" (Pesetsky \& Torrego 2004:2). The number feature is generally considered to be interpretable on nouns, whereas gender in modern Indo-European languages does not seem to make a semantic contribution to the respective lexical items (but see Radford 2004:288, Picallo 2005 and the discussion below). There is a direct relation between the notion of (un)valued features and (un)interpretable features: if a feature (e.g. number) is interpretable under a given category, it enters the derivation with a specified value (e.g. plural). In contrast, if the feature is uninterpretable, it is not specified; it will be valued via agree. That is, uninterpretable features must be deleted before Spell-Out, and in order to be deleted, they must be valued by agree, so that agreement can be understood as directly related to the interpretability of syntactic structures by the semantic component. ${ }^{14}$ Agreement processes are conceived of as 'probing' processes: Unvalued features on a given category item act as a probe and search in their c-

${ }_{13}^{3}$ Cf. Chomsky (2000, 2001, 2005), Radford (2004, chapter 8), Heycock \& Zamparelli (2003), Zamparelli (2004, 2005), Pesetsky \& Torrego (2004), Mensching (2005), Mensching \& Remberger (2006).

${ }^{14}$ For details see Radford (2004:289f.) commanded domain for a suitable goal, i.e. an item with matching valued features. Both, the probe and its goal must be 'active' for agree to apply, i.e. they must contain at least one uninterpretable/unvalued feature. ${ }^{15}$ After match, the operation value takes place: the valued features of the goal are copied onto the probe, which can, but does not have to, instantiate an unvalued feature of its goal. After this agreement process the goal is mobile for syntactic movement.

In order to apply this model, originally conceived for agreement processes at the sentence level (e.g. person and number agreement and nominative case assignment between $\mathrm{T}$ and the subject DP), to the internal structure of nominals (gender and number agreement and its interaction with indefinite determiners) and in order to derive their correct quantificational interpretation, we will use a modified version of Heycock \& Zamparelli's (2003) proposal for English indef inite nominals. Following Heycock \& Zamparelli (2003), we assume first that nouns do not have a specific interpretation with regard to 'count' or 'mass' or anything else but that their denotation is merely a set of singleton elements irrespective of their morphological number (cf. Heycock \& Zamparelli 2003:13 for a detailed argumentation). The interpretation of a nominal as being 'semantically pluralized', i.e. as denoting "a set composed in all the ways in which these [elements, E.S.] can be grouped together into pluralities" (as "having a join semilattice structure", with the notation [+LATT]) is created by merge of a noun with a functional head, ' $P l^{*}$ ' which operates semantic pluralization (i.e. creates a 'semilattice interpretation', cf. Link 1983). The semantic feature $[ \pm$ LATT] is introduced by Heycock \& Zamparelli (2003) in order to describe the contribution of the functional head $\mathrm{Pl}^{*}$ to the interpretation of the whole nominal. $\mathrm{Pl}^{*}$ creates sets of sets of different sizes out of the set of singleton elements denoted by the NP:

For example, with 4 individual tall boys $a, b, c, d$ in the domain, [ ${ }_{N P}$ tall boys] will denote $\{\{a\},\{b\},\{c\},\{d\}\}$, and PIP will be:

$\|[$ pIP tall boys] $\|=\{\{a, b, c, d\},\{a, b, c\},\{b, c, d\}\{a, c, d\},\{a, b, d\},\{a, b\},\{a, c\}$, $\{a, d\},\{b, c\},\{b, d\},\{c, d\},\{a\},\{b\},\{c\},\{d\}\}$

At the next level up, NumP behaves as a filter. It regulates the cardinality of the PIP

denotation, eliminating from it all the pluralities with the wrong number of atoms $[\ldots]$.

(Heycock \& Zamparelli 2003: 13)

This denotation of plural noun phrases is parallel to the one of mass terms, which also denotes sets of sets of portions of the same substance (cf. Link 1983). Later we will mention some structural parallels between plural noun phrases and non-countable nominals, independent of morphological number and demonstrating the relevance of the [LATT]-feature in the nominal derivation. The functional head $\mathrm{Pl}\left({ }^{*}\right)$ is also responsible for the morphological number agreement inside the nominal. Heycock \& Zamparelli (2003) work

\footnotetext{
is Cf. Radford (2004:289ff.)
} 
within a framework which still assumes feature checking, as in earlier versions of minimalism, and they apply the checking mechanism both for morphological/grammatical and semantic features (essentially number and [ \pm LATT]), whereas we will apply the probe-model and assume agree processes only between grammatical attribute-value pairs. Thus, in our framework the number feature of $\mathrm{Pl}(*)$ is unvalued $([\mathrm{Nb}:])$ and acts as a probe. This feature will be valued by agree with the lexical noun (cf. 6a) and gets deleted after valuation (cf. $6 \mathrm{~b}$ ), i.e. it gets invisible to the semantic, but remains visible to the phonological component. The interpretation of the nominal depends ultimately on the different properties of the heads in the derivation and on the interaction of different agreement processes in the structure:

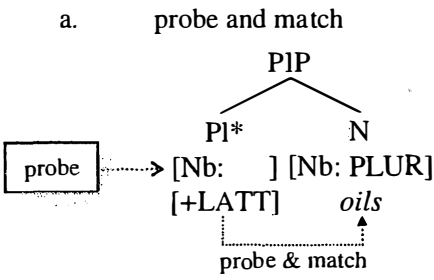

b. value and delete

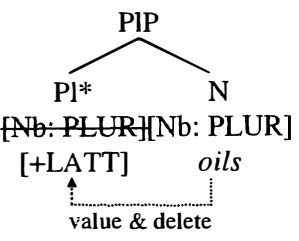

Note that, in this derivation, $\mathrm{N}$ does not have any uninterpretable features and is thus theoretically not 'active' in the sense described above. On the other hand, the probe in $\mathrm{Pl}\left({ }^{*}\right)$ has to be instantiated for morphological number - and there is only one matching element in its c-commanded domain, $\mathrm{N}$, with a valued $\mathrm{Nb}$ feature. For English nominals, therefore, we have to assume ${ }^{16}$ that agree takes place in this way, given the fact that the probing operation cannot take place erroneously between a probe and an inadequate goal.

In the next step, PIP can optionally be merged with Num, the head that hosts cardinals, weak quantifiers etc.: ${ }^{17}$

$$
\text { merge with Num }
$$

Since NumP acts as a filter regulating the cardinality of the PIP denotation (see above), only sets containing five elements will be left in the denotation of

${ }^{16}$ Just as Pesetsky \& Torrego (2004:1) seem to assume tacitly for Latin nominals as well.

${ }^{17}$ Cf. Heycock \& Zamparelli (2003:11 ff.).
NumP. Numerals are lexically specified for their semantic [ \pm LATT] feature and have to possess the same [ $\pm \mathrm{LATT}]$ feature as $\mathrm{Pl}(*)$ in order to derive grammatical structure; the numeral "one" has [-LATT], numerals above "one", [+LATT]. Heycock \& Zamparelli 2003 (17f.) assume here a traditional feature checking mechanism between Num and $\mathrm{Pl}\left({ }^{*}\right)$, which avoids, e.g., the ungrammatical structure *one oils. We will not go into any further detail here, given that the problem of explicit quantification by numerals is not central to our discussion. Also, NumP controls number agreement outside the nominal, e.g. in cases where the respective nominal is the sentential subject and has to agree in number with the finite verb.

There are several arguments in favour of assuming that two (rather than only one ${ }^{18}$ ) functional projections are involved in the plural marking of a nominal. One important argument comes from languages like Hungarian, which combines singular $\mathrm{N}$ with cardinals higher than "one":
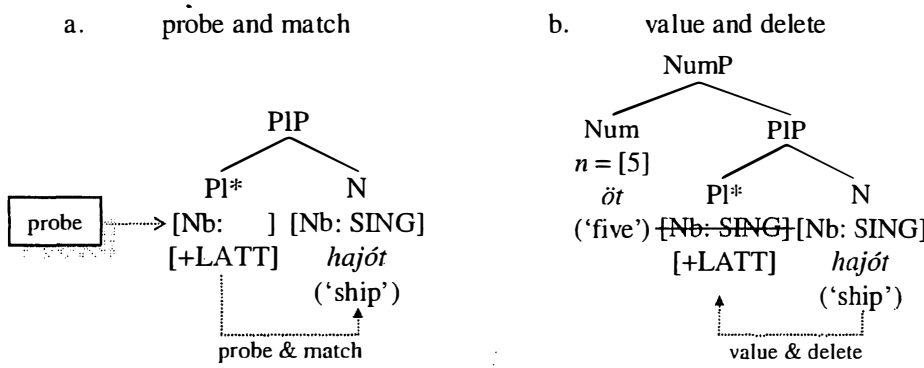

If morphological number agreement and 'semantic pluralization' plus indication or filtering of the correct cardinality were situated in the same functional projection, say Num, the Hungarian structure could not be accounted for, as Num would host two contradictory features, i.e. the cardinality "five", thus selecting a set of five elements out of a set of sets and regulating morphological plural agreement outside the nominal, and a probe being valued with morphological singular number inside the nominal.

Most importantly for our argumentation, by separating morphological and semantic number (SING vs. PLUR and [ \pm LATT]), Heycock \& Zamparelli (2003) can account firstly for the difference between 'count' and 'mass' readings of singular nouns in languages like modern English, German or Spanish and secondly for the striking parallels in the syntactic behaviour of singular mass and plural nominals in many languages: In these languages, it is not the noun itself that carries [ \pm LATT] information, nor is it the morphological number of a nominal, as virtually any noun can appear in both a countable or

${ }^{18}$ Like Ritter (1993 and subsequent work) with NumP only 
non-countable nominal. It is merge of $\mathrm{N}$ with $\mathrm{Pl}^{*}$ irrespective of the morphological number of $\mathrm{N}$ which creates a [+LATT] denotation. ${ }^{19}$

Now, what happens if $\mathrm{N}$ is not merged with $\mathrm{Pl}^{*}$ and is therefore not semantically pluralized? In the case of a singular $N$, a default element, the indefinite article, has to enter the enumeration in order to derive the [-LATT] denotation:
(9)

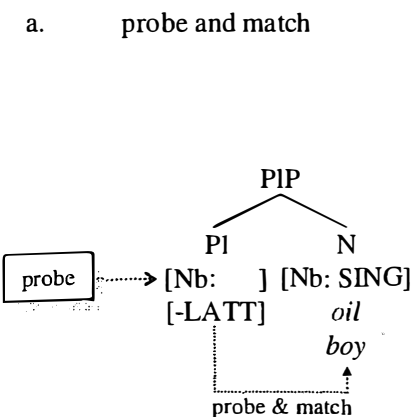

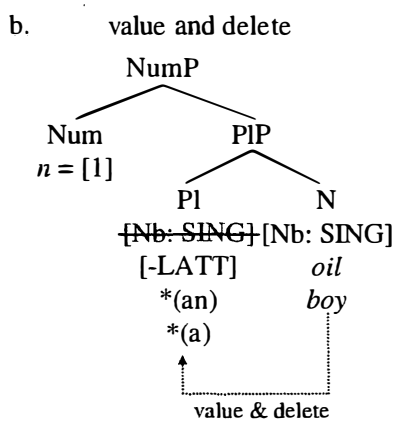

According to Heycock \& Zamparelli (2003), the obligatory presence of $a(n)$ in a structure of this type is due to the fact that Pl would not contribute anything semantically to the denotation of the whole nominal. They further assume that a functional head which is semantically inactive and phonologically empty should not exist in the structure. ${ }^{20}$ Alternatively, we could say that the [ \pm LATT]-feature in $\mathrm{Pl}(*)$ needs an overt expression in a language for one or the other value, the opposite value being implicated in the absence of overt coding. Furthermore, $\mathrm{Pl}\left({ }^{*}\right)$ is syntactically necessary for phrase internal morphological number agreement, which does not automatically coincide with external morphological number agreement (cf. Fr. la plupart des gens fument, Engl. this/*these committee are to meet tomorrow). This is enough reason to assume its existence inside (indefinite) nominals (see below). Be it as it be, in the case of the absence of $\mathrm{Pl}^{*}$, the $\mathrm{Pl}$ position in English is filled with an element providing the [-LATT] interpretation for the whole nominal, thus disambiguating overtly the semantic interpretation of the whole structure. Contrary to the Romance languages and their indefinite article deriving from the Latin numeral unus (see below), English $a$ is merged in $\mathrm{Pl}$ on the basis of different distributional properties (cf. the impossible literal translation into Romance of the English many a time, too tall a boy etc.). ${ }^{21}$ Functionally, the obligatory indefinite article in Romance countable nominals assumes the parallel coding of [-LATT], among others functions (see below).

\footnotetext{
${ }^{19}$ Cf. Heycock \& Zamparelli (2003:16f.)

${ }^{20}$ Cf. Heycock \& Zamparelli (2003:17). This is also in complete accordance with Economy Principles assumed already in Chomsky 1995.

${ }^{21}$ Cf. Heycock \& Zamparelli (2003:17f.).
}

3.2 Romance languages: gender, number and 'classification'

How can we now relate this model to our initial problems, i.e. the striking differences between French, Italian and Spanish with regard to their systems of indefinite determiners, the possibility of having bare nominals in argument position and the respective language change from Latin to Romance? First of all, Romance languages and Latin have overt gender as an additional $\varphi$ feature besides number, a feature which is usually considered to be uninterpretable. As gender is expressed overtly at least on some cardinals, weak quantifiers and the indefinite article. and as it has to be valued there in order to be deleted, ${ }^{22}$ there has to be a probe for gender in Num, ${ }^{23}$ and there will be two subsequent agree operations to carry out, the first one for morphological number between $\mathrm{Pl}^{*}$ and $\mathrm{N}$ (but see below) and the second one for morphological gender between Num and $\mathrm{N}\left(\mathrm{Pl}^{*}\right.$ in Spanish is not a matching goal for the probe for gender). Num controls gender agreement inside the nominal. A structure like the following one must accordingly be assumed for Spanish:

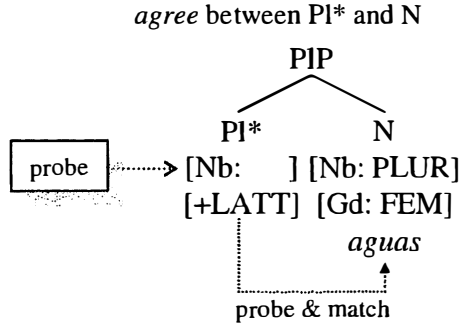

(10) b

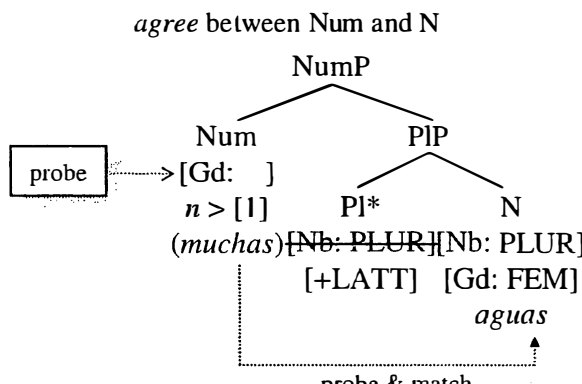

${ }^{22}$ Cf. Heycock \& Zamparelli (2003:19f.).

${ }^{23}$ This, then, is an explanation for the necessary location of gender in Num: due to the mechanism of agree and feature deletion immediately after merge (cf. the 'Earliness Principle' which requires operations, especially agree, to apply as early as possible in a derivation, cf. Radford 2004:282), gender cannot be a probe together with number in $\mathrm{Pl}\left({ }^{(*)}\right)$, as it would get valued and deleted. 
(10)c. resulting configuration

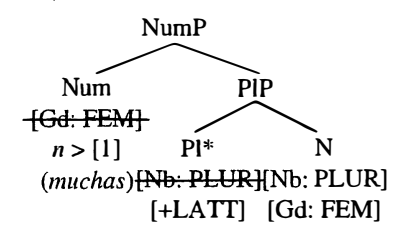

aguas

In the case of agua, we would get un(a) for P1 [-LATT] just like in English. Yet, in Spanish and in Romance in general the indefinite article is located in Num, because it also realizes the gender feature of this category. In Spanish, after full instantiation of the probes, $\mathrm{N}$ can additionally move from its position at least up to Num and further to D (as only DPs are arguments in Romance, cf. Chierchia 1998 and Longobardi 2001b) and can thus appear as a bare plural in argument position (cf. also Picallo 2005:110, though assuming a slightly different denomination and function for $\mathrm{Pl}(*)$, see below). The gender feature of $\mathrm{N}$ remains undeleted in this and the following derivations, because it is considered to be interpretable, roughly following Picallo 2005, who assumes that "gender declension is the morphological exponent of an abstract interpretable feature in the functional layer of nominal structures" (Picallo 2005:107ff.), an 'abstract classification feature' (cf. also Harley \& Ritter 1999, 2002a,b for a feature geometric approach to pronouns, where gender is the specification under a 'classification node'). Note that, theoretically, a probe for gender could also be situated in $\mathrm{Pl}\left({ }^{*}\right)$ together with the number probe (as proposed in Picallo 2005 for Spanish and Catalan). However, the below discussion of Italian and especially French will show that the assumption of two different probes in two different heads, one for gender in Num and one for number in $\mathrm{Pl}\left({ }^{*}\right)$, makes clearer predictions for the syntactic behaviour of indefinite nominals in the respective languages. We will try to show in the following that the gender feature is ultimately indirectly related to the semantic [ \pm LATT] feature introduced by Heycock \& Zamparelli 2003. The problem is that the location of gender varies in the Romance languages, and the complete syntactic and semantic structure of Romance nominals can only be obtained by assuming a complex interplay between the functional heads Num and $\mathrm{Pl}(*)$ and their respective number and gender features.

As has been pointed out in section 2, French nouns do not have a morphological marker for gender and number. They could be analysed as having lost any grammatical features and as not contributing to an agreement phenomenon of any kind. The only information they provide is their descriptive semantic content. Accordingly, morphological number must be specified and interpreted elsewhere, for example in NumP, by obligatorily inserted lexical items which bear a valued number but an unvalued gender feature. A probe for gender is situated in Num, and agree will therefore take place not between Num and/or $\mathrm{Pl}\left({ }^{*}\right)$ with $\mathrm{N}$ as in English or Spanish. but between Num and $\mathrm{Pl}\left({ }^{*}\right)$ only. We should remember that, in Romance, NumP is the place for gender agreement inside and outside the nominal (cf. Heycock \& Zamparelli 2003:19f.). Additionally, we assume that, for French at least, number is valued (and interpretable) in NumP and has to be assigned to $\mathrm{Pl}\left({ }^{*}\right)$ after the agree operation (remember that fully valued probes can after value assign unvalued features to their goals, like the person-number-gender probe in $\mathrm{T}$ assigns nominative case to its 'goal DP', see above, the beginning of section 3.1). Evidence for this comes from the morphological difference between plural and singular determiners in French - as on $\mathrm{N}$ in Spanish, the inflectional endings of the French determiners indicate unambiguously whether a nominal is plural (obligatorily ending in [-e]) or not. $\mathrm{Pl}\left({ }^{*}\right)$ is visible/active to the probe in Num because its number feature is again not valued, but it is not itself a probe. For this unvalued feature we will use the notation $([\mathrm{Nb}: \mathrm{A}]) .{ }^{24}$ After valuation of the gender probe of Num, the number value can be assigned to $\mathrm{Pl}\left({ }^{*}\right)$ (and deleted afterwards). The derivation of French nominals is as follows:

agree between Num and $\mathrm{Pl}^{*}$

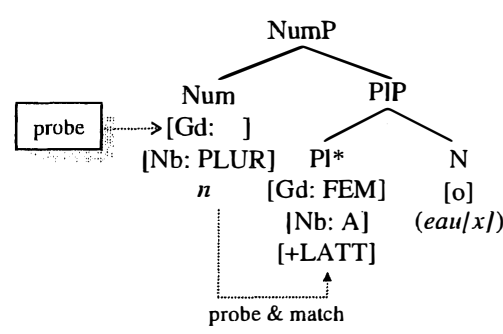

(11)b

$$
\text { resulting configuration }
$$

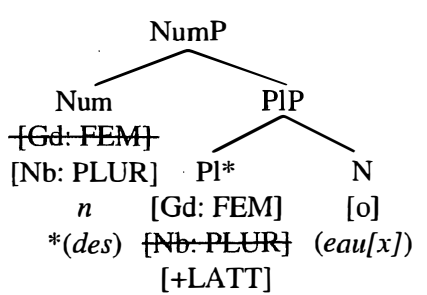

\footnotetext{
${ }^{24}$ Note that his unvalued feature does not act as a probe. It is comparable to the unvalued Case feature of $\mathrm{N}$.
} 
During this agree operation the unvalued feature for number of $\mathrm{Pl}^{*}$, which doesn't act as a probe, is instantiated. That is, the agree operation also serves for assigning number to $\mathrm{Pl}^{*}$. Thus, as French nouns do not participate in agreement processes at all, they remain totally disabled for movement to D for this reason, bare noun phrases cannot appear in argument position in French. In contrast to Spanish, and because of the lack of number information in $\mathrm{N}$ and $\mathrm{Pl}(*)$, French indefinite singular noun phrases exhibit a morphological element for singular nominals with a [+LATT] interpretation, the 'partitive article', indicating morphological number and [+LATT]:

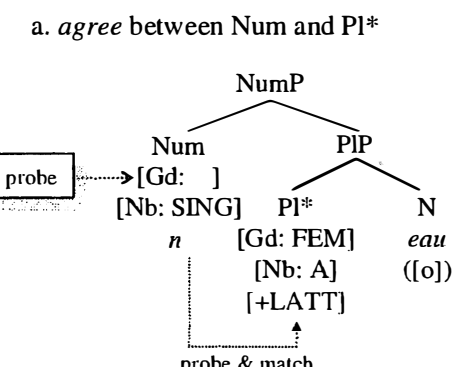

b. resulting configuration

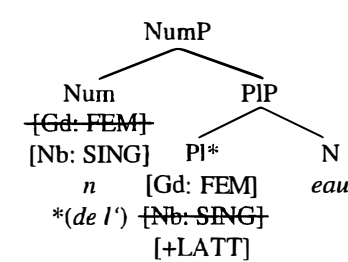

Please note that, in the derivations (11) and (12), the number feature remains undeleted in Num, just like the gender feature in $\mathrm{Pl}^{*}$. We will come back to this later.

French countable nominals are to be derived in the following way:

agree between Num and $\mathrm{Pl}$ :

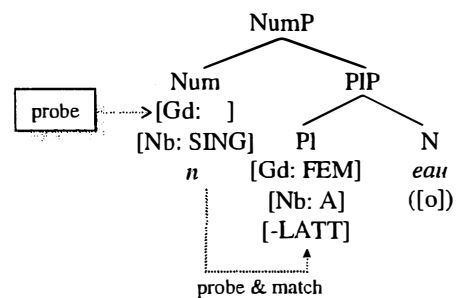

(13) b

$$
\text { resulting configuration: }
$$

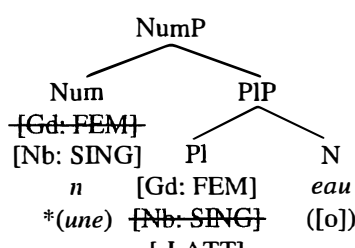

[-LATT]

Just as in English, the indefinite article un(e) has to appear obligatorily with French singular countable noun phrases; however, it has to do so in order to indicate the [-LATT] interpretation (it also appears higher in the structure than English $a$, cf. Heycock \& Zamparelli 2003:17f.) and to indicate singular number.

Italian now has overt expression of number, but this is quite ambiguous, whereas gender, at least for the overwhelming majority of nouns ending in - $o$ and $-a$, is marked on the noun and therefore assumed to be a valued feature on $\mathrm{N}$ here:

(14) a.

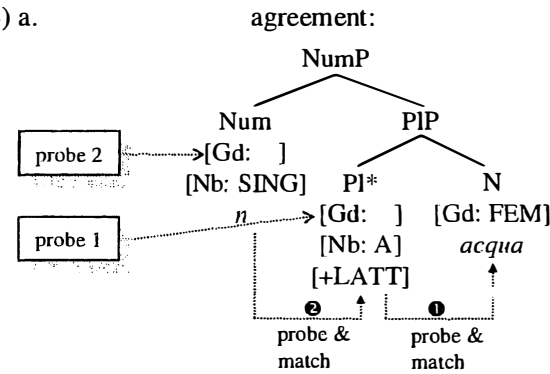

(14)b.

$$
\text { resulting configuration: }
$$

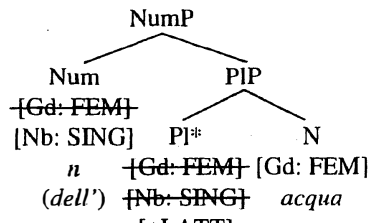

[+LATT]

This makes two subsequent agree operations necessary: first, one between the gender probe of $\mathrm{Pl}^{*}$ and $\mathrm{N}$, and second, one between the gender probe of 
Num and $\mathrm{Pl}^{*}{ }^{25}$ During this second agree operation the unvalued feature for number of $\mathrm{Pl}^{*}$, which doesn't act as a probe, is instantiated. That is, the second agree operation also serves for assigning number to $\mathrm{Pl}^{*}$, like in French. Just as in Spanish, there are two agree operations, but this time two for gender. The main difference to Spanish lies in the fact that morphological number agreement takes place between Num and $\mathrm{Pl}^{*}$ and not between $\mathrm{Pl}^{*}$ and $\mathrm{N}$.

Here we can find a structural explanation for the empirical correlation of unambiguous number marking on the one hand and the absence of a 'partitive article' on the other. Thus, if agree has to take place between Num and $\mathrm{Pl}\left({ }^{*}\right)$, the former possesses an element marking singular or plural, especially for nominals with a [+LATT] interpretation. Furthermore, only if morphological number cannot be obtained at all via the complex interplay between gender and number features in the structure, as it still can be in Italian (the ending - $e$ e.g. is disambiguated as to its number feature, when the feminine or masculine gender is clear), this 'partitive' element will be obligatory, as in French. We can also already understand the second correlation, the one between bare nominals (plurals) in argument position (Italian, Spanish vs. French) and the expression of gender as an overtly coded feature on $\mathrm{N}$. In this case, $\mathrm{N}$ takes part in an agree operation between $\mathrm{N}$ and $\mathrm{Pl}\left({ }^{*}\right)$, and even in one between $\mathrm{N}$ and $\mathrm{Num}$ or Num and $\mathrm{Pl}\left({ }^{*}\right)$ - and after these operations have taken place, it can move upwards in the structure into a functional projection compatible with argumenthood in Romance languages like D.

As a further illustration of this, let us have a look at the derivation of Italian indef inite plural nominals:

(15)a.

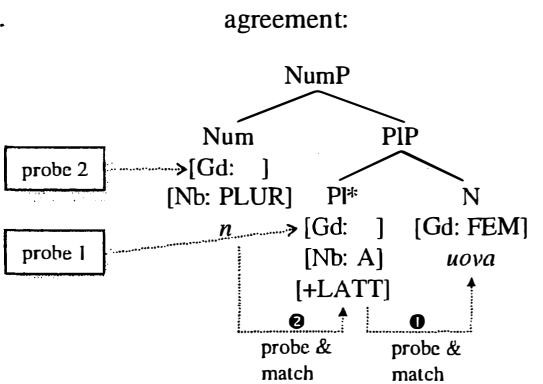

${ }^{25}$ Please note that, according to the "Feature Visibility Convention" in Radford (2004:289), a deleted feature like the gender feature in $\mathrm{PI}\left({ }^{*}\right)$ after merge and agree with $\mathrm{N}$ remains visible to the syntax and PF even if it becomes invisible for the semantic component after deletion, so that the gender feature there can represent a matching feature for the gender probe in Num after merge with PIP. (15)b.

resulting configuration:

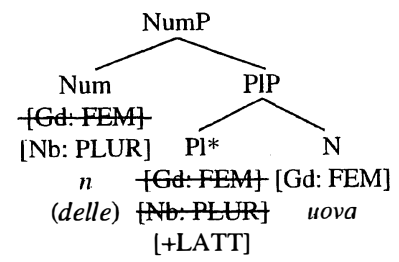

Finally, with a countable nominal:

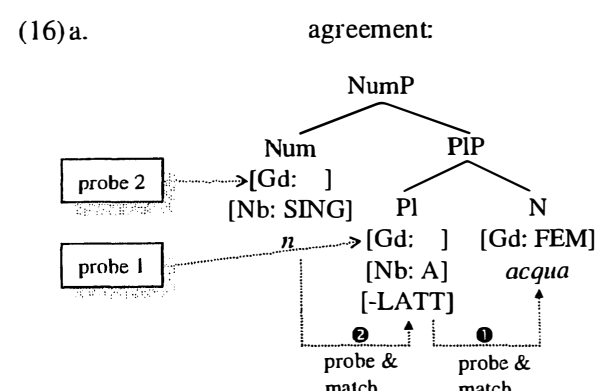

(16)b.

resulting configuration:

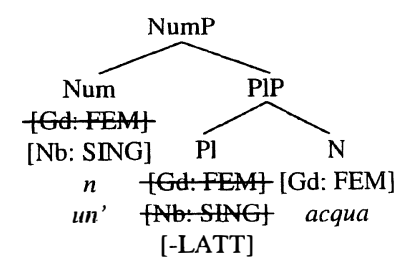

Again, there is an obligatory insertion of the indefinite article in order to derive the [-LATT] property of the whole nominal in Num, but not in Pl because of the gender feature.

\section{From Latin to Romance: what happened in the structure?}

As Latin nouns are inherently specified (and marked) for gender and number and as, at least for concrete denotations, the combination of gender (especially neuter) and number gives relatively clear-cut information on the 'classification' of the intended referent (cf. section 2), we assume that the [ \pm LATT] feature is a lexical feature on nouns in Latin, the functional projection 
Pl having only a probe for number. Indefinite nominals in Latin thus have the following structure:

(17) a

$$
\text { neuter nouns: }
$$

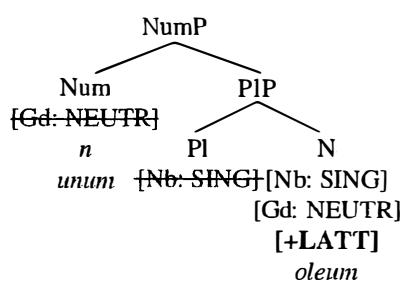

(17)b.

$$
\begin{aligned}
& \text { feminine nouns: } \\
& \text { [-LAd: FEM] } \\
& \text { [-LATT] } \\
& \text { olea }
\end{aligned}
$$

If we abstract away from the Latin case marking system, there is a gender probe in Num in this derivation, as Latin indefinite determiners and quantifiers, including numerals, can be marked for gender, just like it has been assumed for modern Romance languages. However, Pl does not have a [ \pm LATT] feature responsible for 'semantic pluralization' - the interpretation of the denotational characteristics of the whole nominal is a feature of $\mathrm{N}$. This is reflected by the fact that there is no direct association in Latin between morphological plural and [+LATT], as has been shown above in section 2 . Thus, the number probe and the $[ \pm \mathrm{LATT}]$ feature have to be separated in languages without a grammaticalized 'countability distinction'.

Now, imagine a system which loses to a considerable extent its gender- and number marking devices through the (partial) loss of inflectional endings - like Late Latin: not only case, but also number and especially gender, carrying the most important conceptual distinction ('apprehension', 'classification') besides (in)definiteness for a nominal to be an argument. Of course, the speakers of this system can 're-analyse' its numeral(s), especially "one", as a 'countability marker' and as a singular marker and thus compensate for the inflectional classification system. However, this appealing functional explanation is too simplistic when it comes to the details of syntactic computation:
(18)

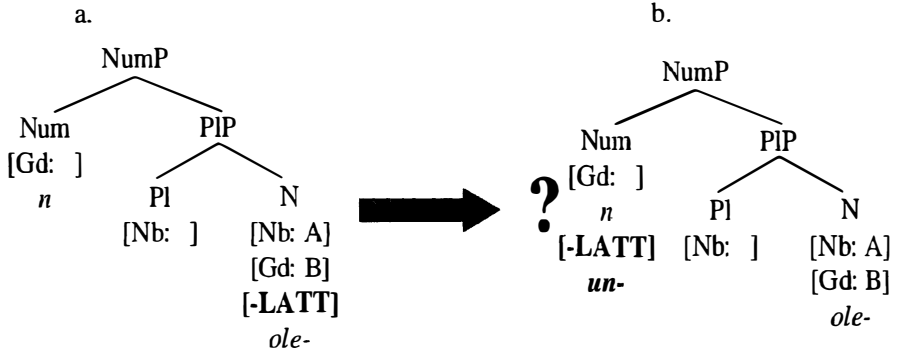

Reanalysis defined in its original acceptation as a "change in the structure of an expression or class of expressions that does not involve any immediate or intrinsic modification of its surface manifestation" (Langacker 1977:58) could be seen here in the rearrangement in the feature structure of Num. But there are considerable problems for the modelling of gender and number agreement (unvalued gender feature in Num, no value for the number feature etc.) inside indefinite Late Latin and future Romance nominals, so that the right-hand derivation is simply not acceptable.

What exactly happened during the syntactic evolution from Latin to Romance, then? How can we adequately describe and explain the actual syntactic make-up of Romance together with its differences from Latin, which are also topologically relevant? Please have a look at the following structure, which evolved from the left-hand one in the above Latin derivation:
(19)

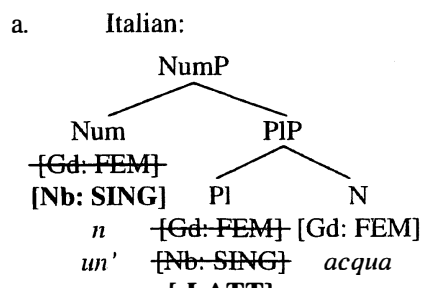

b. French

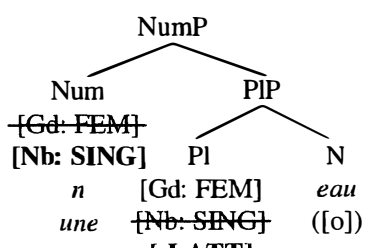

[-LATT]
The reanalysis of "one" as a countability marker and the whole 'countability grammaticalization' that took place after the Latin declension system broke down led to the dichotomic coding of [ $\pm \mathrm{LATT}]$ in $\left.P l l^{*}\right)$ as the new location for 'semantic pluralization', but also as a key projection for the internal gender and number agreement inside Romance nominals. ${ }^{26}$ In central

26 Cf. the definition of grammaticalization in Roberts \& Roussou 2003: "[...] grammaticalization is reanalysis 'upwards' along the functional structure. Since movement is always local and upward, categorial reanalysis is also local and upward" (Roberts \& Roussou 2003:71). 
Romance languages like French and Italian, where number marking is problematic on $\mathrm{N}$ (gender marking as well in French), the number feature appears in $\mathrm{Pl}\left({ }^{*}\right)$, as has been postulated for English or Hungarian on the basis of independent facts by Heycock \& Zamparelli (2003) (see section 3.1 above). This number feature is unvalued and has to receive a value by agree, but cannot be a probe, and for this reason, an additional agree operation has to take place between Num and $\mathrm{Pl}\left({ }^{*}\right)$ without directly or exclusively involving $\mathrm{N}$ (as in Latin). There is now a valued number feature in Num, together with the original gender probe, while a valued gender feature for French is situated in $\mathrm{Pl}\left({ }^{*}\right)$.

One, for example a functionalist, could now ask why the assumption of a functional projection, $\mathrm{Pl}(*)$, with a [ \pm LATT] feature, would be necessary in order to account for the morphosyntactic facts in modern Romance. The location of a valued number feature in Num seems to be enough, together with the re-interpretation (rather than the re-analysis) of "one" as a countability marker. Now, besides the fact that the assumption of creating (morphological and semantic) plurality in Num and filtering it at the same time has been rejected on independent grounds by Heycock \& Zamparelli (see section 3.1 above), it also does not solve our agreement problems, and, more importantly still, it does not allow us to understand the interaction of noun morphology, nominal classification and nominal determination discussed in section 2 above. It would not give evidence for the obligatory insertion of the numeral "one" in Num in indefinite singular countable nominals. Gender seems to play a key role in this story, and, both historically and functionally, it makes perfect sense that it should do so in relation to a head with a $[ \pm$ LATT] feature: gender classes are assumed to have been directly related to extra-linguistic referent classes in Proto-Indo European (cf. Schön 1971, Windisch 1973). Also, in our model the gender feature is situated in $\mathrm{Pl}\left({ }^{*}\right)$, either as a probe (Italian) or as a valued feature (French) - the functional projection now responsible for 'semantic pluralization' and, more than anything else, for the correct derivation of a 'mass' or 'count' reading of the (singular) nominal. All of this is only indirectly related to the filtering of the correct quantity that is done in Num (see section 3.1 above). Also, if we compare the structures of (12b) and (14b) above with the one for Spanish (and other Romance languages with unambiguous plural marking) in (20), we can derive the possibility or the need for a 'partitive article' in Italian and French:
(20)

\section{Ibero Romance}

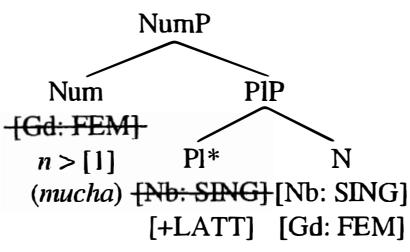

agua

This structure, derived from the defective one in Late Latin, now with a [ \pm LATT]-feature in $\mathrm{Pl}\left({ }^{*}\right)$ like in English, is fundamentally different from the central Romance one: just as in Italian, two agree operations have to take place, and the result is the possibility of moving $\mathrm{N}$ to a higher projection in order to make it available for argument position even if it is bare. In contrast to Italian and French, however, there is no association of gender with the [ \pm LATT] feature in $\mathrm{Pl}\left({ }^{*}\right)$, and there is therefore no 'classification' system and no explicit marking for the [+LATT] value in the singular case - the 'partitive article'. This could not be explained if we assumed that gender and number were both situated in Num and functioned as a probe (Spanish), as a partial probe (Italian) or as valued features (French).

\section{Conclusion}

In this paper, I have tried to describe and explain the grammatical change in the evolution of some devices of 'nominal classification' in a broad sense from Latin inflectional nominal endings (overt gender and number marking) to Romance indefinite determiners. Comparing the noun morphology and the need for indefinite determination in argument position in French, Italian and Spanish allowed us to observe two main correlations: firstly, the possibility of bare arguments (Italian and Spanish vs. French) correlates with the preservation of a quite clear-cut overt gender marking morphology on the noun (in contrast to Delfitto \& Schroten 1991, who see an interdependency with number marking); secondly, unambiguous number marking correlates with the absence of a classifier for 'mass readings' (the 'partitive article': Spanish vs. French and Italian). If the loss of nominal declensional endings in Latin is analysed as the loss of the marking of the fundamental 'mass-count distinction' via noun morphology, the rise of the numeral "one" as an indefinite article indicating 'countability', a functional and typologically consistent analysis, is easily motivated. However, only fine-grained formal analyses of the different agreement processes inside indefinite nominals in different Romance languages based on Chomsky's 'probe model' have revealed the syntactic change in Romance nominals which, just as it did for definite nominals with overt D-marking, led to the assumption of new features in $\mathrm{Pl}\left({ }^{*}\right)$ (and Num), as a head responsible 
now for the semantic [ \pm LATT] feature. This assumption is consistent with other syntactic accounts of the change from Latin to Romance, the great majority of which show a tendency towards the explicit marking of former inherent (semantic or pragmatic) features. ${ }^{27}$

$\mathrm{Pl}\left({ }^{*}\right)$ and its feature make-up seems to play a central role in determining the morphological structure and syntactic behaviour of Romance indefinite nominals: if there is a gender feature, whether unvalued or valued (i.e. interpretable, see also section 3.2 above) in $\mathrm{Pl}(*)$ (besides Num), explicit markers of [ \pm LATT] for the singular exist (the indefinite and the 'partitive' article) and are merged in Num, inducing an agree operation between Num and $\mathrm{Pl}\left({ }^{*}\right)$ for number, and, in Italian, one for gender between $\mathrm{Pl}\left({ }^{*}\right)$ and $\mathrm{N}$ (thereby valuing the former uninterpretable gender feature; $\mathrm{Pl}\left({ }^{*}\right)$ is therefore always the syntactic location with an interpretable gender instance). The question of the interpretability of features would thus be in line with the conception proposed in Pesetsky \& Torrego 2004: "an uninterpretable feature must enter an Agree relation with an interpretable counterpart" and the requirement that "every feature must have at least one interpretable instance" (Pesetsky \& Torrego 2004:8). This analysis is also quite parallel to the one presented in Picallo 2005, who assumes a functional projection $c$ ('class') directly above $\mathrm{N}$ in which gender and number features are situated together; Picallo further assumes that "gender declension is the morphological exponent of an abstract interpretable feature in the functional layer of nominal structures" (Picallo 2005:107), this feature being non-overt in Romance (cf. Picallo 2005:109). Now, while Heycock \& Zamparelli 2003 concentrate on morphological number in relation to 'nominal classification', Picallo 2005 considers gender to be central here, assuming that number features always depend on the expression of gender (which is true for Spanish and Catalan but much less obvious for Italian or French). By separating gender and number agreement processes in indefinite nominals in Romance on the one hand, as I propose here in contrast to Ritter 1993, and observing their interaction on the other, as also proposed here, the derivation of both intranominal morphological agreement and indefinite determination becomes obvious. If $\mathrm{Pl}\left({ }^{*}\right)$, which is responsible for morphological number agreement inside the nominal, hosts the gender information in order to cause the uninterpretable gender feature in Num to be valued and deleted, there will be an overt element for this for either case (the indefinite article or the so-called 'partitive article'). This is done via the number probe or the number feature valued in Num, thus triggering the agree process. If $\mathrm{Pl}\left({ }^{*}\right)$ only hosts a number feature, with gender and number features being present on the $\mathrm{N}$ as in Spanish, there will be no overt element for the semantic feature [+LATT] in $\mathrm{Pl}^{*}$ for the singular.

\footnotetext{
${ }^{27}$ Cf. e.g. Longobardi 2001a for definiteness and D.
}

Finally, if $\mathrm{N}$ is not involved in an agree operation of any kind, it will not be enabled for syntactic movement to a higher projection, and consequently bare nominals will not be able to appear in argument position, which is true for French but not for Italian and Spanish.

The formal account presented only as a sketch in this paper and based on independent assumptions has allowed us to derive and explain the syntactic behaviour of Romance indefinite nominals in opposition to the morphosyntactic regularities of Latin, and this in a much more detailed way than any (diachronic) functionalist description of the facts would have been capable of. Functional considerations are important for uncovering the general cognitive motivations for innovations in languages and changing systems; they are related to the interaction of the interfaces with the syntax, but in principle they are too general and extra-linguistically driven to be able to explain morphosyntactic regularities in language change related to the 'narrow syntax'.

\section{REFERENCES}

Chierchia, Gennaro. 1998. "Reference to kinds across languages". Natural Language Semantics 6:4. 339-405.

Chomsky, Noam. 1995. The minimalist program. Cambridge, Mass.: The MIT Press.

------. 2000. "Minimalist Inquiries: The framework". Step by Step. Essays on Minimalist Syntax in Honor of Howard Lasnik, ed. by Roger Martin, David Michaels \& Juan Uriagereka, 89-151. Cambridge, Mass: The MIT Press.

-------. 2001. "Derivation by phase". Ken Hale: A Life in Language, ed. by Michael Kenstowicz, 1-52. Cambridge, Mass: MIT Press.

-----. 2005. On phases. Ms.

Delfitto, Denis \& Jan Schroten. 1991. "Bare plurals and the number affix in DP”. Probus 3:2. 155-185.

Gil, David. 1987. "Definiteness, noun phrase configurationality, and the countmass distinction". The representation of (in)definiteness, ed. by Eric J. Reuland \& Alice G.B. ter Meulen, 254-269. Cambridge, Mass.: MIT Press.

Givón, Talmy. 1981. "On the development of one as an indefinite marker". Folia Linguistica Historica II. 35-53.

Harley, Heidi \& Elizabeth Ritter. 1999. Meaning in Morphology: Motivating a feature-geometric analysis of person and number. MS, .University of Calgary \& University of Pennsylvania.

-. 2002a. "Person and number in pronouns: a feature-geometric analysis". Language 78. 482-526.

------. 2002b. "Structuring the bundle: a universal morphosyntactic feature geometry." Pronouns - Grammar and Representation, ed. by Horst J. 
Simon \& Heike Wiese, 23-39. Amsterdam \& Philadelphia: John Benjamins.

Harris, James W. 1992. "The form classes of Spanish substantives". Yearbook of Morphology 1991, ed. by Geert Booij \& Jaap van Marle, 65-88. Dordrecht: Kluwer.

Haspelmath, Martin. 1999. "Optimality and diachronic adaptation". Zeitschrift fiir Sprachwissenschaft 18:2. 180-205.

Heycock, Caroline \& Roberto Zamparelli. 2003. Friends and colleagues: Plurality, coordination, and the structure of DP. Ms, University of Edinburgh \& Università di Bergamo.

Hofmann, Johann Baptist. 1997 (2nd reprint of the first edition of 1965/1972). Lateinische Syntax und Stilistik: mit dem allgemeinen Teil der lateinischen Grammatik. Neubearbeitet von Anton Szantyr. München: Beck.

Iturrioz Leza, José Luis. 1986. "Individuation and determination III: The concept of verbal plurality and the pluralization of abstractives". Función 1:2. 201-308.

Korzen, Iørn. 1996. L'articolo italiano fra concetto ed entità. Uno studio semantico-sintattico sugli articoli e sui sintagmi nominali italiani con $e$ senza determinante - con un'indagine particolare sulla distribuzione del cosidetto 'articolo partitivo'. 2 vols. Kopenhagen: Museum Tusculanum Press.

Kühner, Raphael \& Carl Stegmann. ${ }^{3}$ 1955. Ausführliche Grammatik der lateinischen Sprache. Satzlehre. Erster Teil. Leverkusen: Gottschalksche Verlagsbuchhandlung.

Langacker, Ronald W. 1977. "Syntactic Reanalysis". Mechanisms of Syntactic Change (Austin), ed. by Charles N. Li. 57-139. Santa Barbara: University of California.

Lehmann, Christian. 1991. "The Latin nominal group in a typological perspective". New studies in Latin linguistics. Selected papers from the $4^{\text {th }}$ international colloquium on Latin linguistics, Cambridge, April 1987, ed. by Robert Coleman, 203-232. Amsterdam \& Philadelphia: John Benjamins.

Link, Godehard. 1983. "The logical analysis of plurals and mass terms". Meaning, use and interpretation of language, ed. by Rainer Bäuerle, Christoph Schwarze \& Arnim von Stechow, 302-323. Berlin: de Gruyter.

--- 1991. "Plural". Semantik. Ein internationales Handbuch der zeitgenössischen Forschung, ed. by Arnim von Stechow \& Dieter Wunderlich, 418-440. Berlin \& New York: Mouton de Gruyter.

Löbel, Elisabeth. 1993. "On the parametrization of lexical properties". The parametrization of universal grammar, ed. by Gisbert Fanselow, 183-199. Amsterdam \& Philadelphia: John Benjamins.

Longobardi, Giuseppe. 2001a. "The structure of DPs: some principles, parameters and problems". The handbook of contemporary syntactic theory, ed. by Mark Baltin \& Chris Collins, 562-603. Oxford \& Cambridge, Mass.: Blackwell.

--------. 2001b: "How comparative is semantics? A unified theory of bare nouns and proper names". Natural Language Semantics 9:4. 335-369.

Meisterfeld, Reinhard. 1998. Numerus und Nominalaspekt. Eine Studie zur romanischen Apprehension. Tübingen: Niemeyer.

Mensching, Guido. 2005. "Sonden und Phasen in romanischen Sprachen". Deutsche Romanistik - generativ, ed. by Georg Kaiser, 123-143. Tübingen: Narr.

-- \& Eva Remberger. 2006. "Probes: lack of agreement in romance". Studies on Agreement, ed. by João Costa \& Maria Cristina Figueiredo Silva, 173-201. Amsterdam \& Philadelphia: Benjamins.

Morani, Moreno. 2000. Introduzione alla linguistica latina. München: Lincom.

Munn, Alan \& Cristina Schmitt. 2005. "Number and indefinites". Lingua 115 821-855.

Pesetsky, David \& Esther Torrego. 2004. The Syntax of Valuation and the Interpretability of Features. Unpublished MS. Boston: MIT.

Picallo, Carme. 1991. "Nominals and nominalizations in Catalan". Probus 3. 279-316.

-----. 2002. . “Abstract agreement and clausal arguments”. Syntax 5:2. 116147.

-------. 2005. "Some notes on grammatical gender and $l$-pronouns". Specificity and the evolution/emergence of nominal determination systems in Romance. Selected papers from the international workshop NEREUS II, October 2004 in Berlin (= Konstanzer Arbeitspapiere zur Sprachwissenschaft, 119), ed. by Klaus von Heusinger, Georg Kaiser \& Elisabeth Stark, 107-121. Konstanz: Universität Konstanz.

Radford, Andrew. 2004. Minimalist Syntax. Exploring the structure of English. Cambridge: CUP.

Ritter, Elizabeth. 1993. “Where's Gender?”. Linguistic Inquiry 82. 146-150.

-. 1995. "On the syntactic category of pronouns and agreement". Natural Language and Linguistic Theory 13. 405-443.

Roberts, Ian \& Anna Roussou. 2003. Syntactic Change. A Minimalist Approach to Grammaticalization. Cambridge: Cambridge University Press.

Schön, Ilse. 1971. Neutrum und Kollektivum. Das Morphem - a im Lateinischen und Romanischen. Innsbruck: Institut für Vergleichende Sprachwissenschaft der Universität Innsbruck.

Șchroten, Jan. 2001. "L'absence de déterminant en espagnol". Typologie des groupes nominaux, ed. by Georges Kleiber, Brenda Laca \& Liliane Tasmowski, 189-203. Rennes: Presses Universitaires de Rennes.

Seiler, Hansjakob. 1986. Apprehension. Language, object, and order. Part III: The universal dimension of apprehension. Tübingen: Narr. 
Stark, Elisabeth. 2002. "Indefiniteness and specificity in old Italian texts". Journal of Semantics 19. 315-332.

-------. 2005. "Explaining article grammaticalization in Old Italian". Romanistische Korpuslinguistik II. Korpora und diachrone Sprachwissenschaft, ed. by Claus D. Pusch, Johannes Kabatek \& Wolfgang Raible, 455-468. Tübingen: Narr.

---. 2006. Indefinitheit und Textkohärenz. Entstehung und semantische Strukturierung indefiniter Nominaldetermination im Altitalienischen (= Beihefte zur Zeitschrift für romanische Philologie, 336), Tübingen: Niemeyer.

---. 2007. "Gender, number, and indefinite articles - about the 'typological inconsistency' of Italian". Evolution and function of nominal determination (= Studies in Language and Linguistic Typology), ed. by Elisabeth Stark, Wemer Abraham \& Elisabeth Leiss, 49-71. Amsterdam \& Philadelphia: John Benjamins.

--. Forthcoming. "Typological correlations in nominal determination in Romance". Proceedings of the Copenhagen Determination Symposium (August 2004), ed. by Alex Klinge et al., Amsterdam \& Philadelphia: Benjamins.

Van Kemenade, Ans \& Nigel Vincent. 1997. Parameters of morphosyntactic change. Cambridge: Cambridge University Press.

Vincent, Nigel. 1997. "The emergence of the D-system in Romance". Van Kemenade \& Vincent 1997. 149-169.

Windisch, Rudolf. 1973. Genusprobleme im Romanischen. Das Neutrum im Rumänischen. Tübingen: Narr.

Zamparelli, Roberto. 2004. "Manufacturing Plurality". Talk given at the Copenhagen Determination Symposium, 26.-28. August 2004.

------. 2005. "The structure of (in)definiteness". Lingua 115. 915-936.
TM The paper used in this publication meets the minimum requirements of American National Standard for Information Sciences - Permanence of Paper for Printed Library Materials, ANSI Z39.48-1984.

\section{Library of Congress Cataloging-in-Publication Data}

The paradox of grammatical change : perspectives from romance / edited by Ulrich Detges, Richard Waltereit.

p. cm. -- (Amsterdam studies in the theory and history of linguistic science. Series IV, Current issues in linguistic theory, ISSN $0304-0763 ; \mathrm{v} .293$ )

Includes bibliographical references and index

1. Linguistic change. 2. Grammar, Comparative and general. 3. Romance languages--Grammar, Historical. 1. Detges, Ulrich. II. Waltereit, Richard.

P142.P365 2008

$440^{\prime} \cdot 045-$ d 922

2007044470

(c) 2008 - John Benjamins B.V.

No part of this book may be reproduced in any form, by print, photoprint, microfilm, or any other means, without written permission from the publisher.

John Benjamins Publishing Co. • P.O.Box 36224 • 1020 ME Amsterdam • The Netherlands John Benjamins North America • P.O.Box 27519 • Philadelphia PA 19118-0519 • USA 